COMMENTARY ON COVID-19 AND THE Food SYSTEM

\title{
Americans' food spending patterns explain devastating impact of COVID-19 lockdowns on agriculture
}

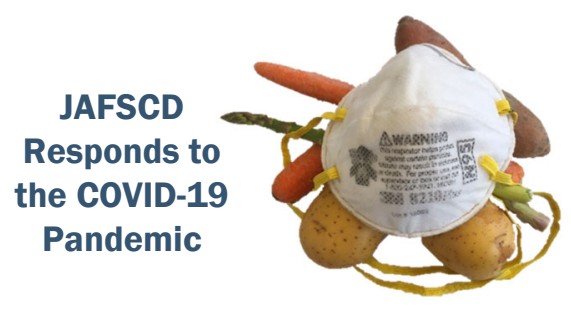

Stephan J. Goetz a and Claudia Schmidt $b *$

Pennsylvania State University

Lisa Chase ${ }^{\mathrm{c}}$

University of Vermont Extension

Jane Kolodinsky d

University of Vermont

Submitted May 2, 2020 / Published online May 21, 2020

Citation: Goetz, S. J., Schmidt, C., Chase, L., \& Kolodinsky, J. (2020). Americans’ food spending patterns explain devastating impact of COVID-19 lockdowns on agriculture. Journal of Agriculture, Food Systems, and Community Development, 9(3), 31-33.

https://doi.org/10.5304/jafscd.2020.093.033

Copyright (C) 2020 by the Authors. Published by the Lyson Center for Civic Agriculture and Food Systems. Open access under CC-BY license.

The U.S. Department of Agriculture Economic Research Service's Food Expenditures by Outlet data provide insight as to why the lockdowns related to COVID-19 have been so devastating for U.S. farmers. In 2018, American consumers bought a total of $\$ 628 \mathrm{bn}^{1}$ worth of food, of which $\$ 460$ bn was spent at grocery stores and \$168bn at warehouse clubs and supercenters (see Figure 1 and Table 1). But expenditures on food away from home exceeded that amount: $\$ 680 \mathrm{bn}$ was spent at restaurants, $\$ 337.8 \mathrm{bn}$ at full-service restaurants and $\$ 340.2 \mathrm{bn}$ at limited-service restaurants. ${ }^{2}$ The social

a Stephan J. Goetz, Northeast Regional Center for Rural Development, Department of Agricultural Economics, Rural Sociology and Extension Education, Pennsylvania State University; 207-C Armsby, University Park, PA 16802-5602 USA; sgoetz@psu.edu

$\mathrm{b} *$ Corresponding author: Claudia Schmidt, Department of Agricultural Economics, Rural Sociology and Extension Education, Pennsylvania State University; 207-D Armsby, University Park, PA 16802-5602 USA; cschmidt@psu.edu

${ }^{\mathrm{c}}$ Lisa Chase, University of Vermont Extension, Brattleboro, VT, USA.

d Jane Kolodinsky, Department of Community Development and Applied Economics, University of Vermont, Burlington, VT, USA

${ }^{1}$ All amounts are in U.S. dollars.

${ }^{2}$ Not all of this represents the value of agricultural products; a large share of this is value-added in the form of rents and wages. 
distancing and stay-at-home orders related to the COVID-19 pandemic have forced many restaurants to close and those remaining in business to switch to pick-up or delivery only options. Because restaurant supply chains are highly specialized and time sensitive, reallocation of these supply chains has not come quickly enough to accommodate the shifts in consumption toward at-home eating patterns.

While other expenditure categories are much smaller, they have experienced marked changes, some in opposite directions. For example, mail order and home delivery volumes, valued at $\$ 24.8 \mathrm{bn}$ and representing only $1.5 \%$ of expenditures in 2018 , have increased markedly in the last month according to anecdotal evidence. On the other hand, schools and colleges, hotels and motels, drinking places, and recreational places - accounting for an additional 12.6\% of food expenditures-have experienced dramatic reductions in demand. Perhaps most remarkable is the fact that Americans devoted only $0.3 \%$ of all expenditures on food to direct selling (these include farmers, manufacturers, and wholesalers) (Elitzak \& Okrent, 2018). Along with mail order and home delivery, direct sales by farmers is one of the few sectors that appears to be growing rapidly during the evolving COVID-19 pandemic, despite social distancing-related constraints.

The COVID-19 pandemic has resulted in historically unprecedented shocks to the U.S. economy, and, by extension, to the food system. Never before have entire sectors of the economy been shut down, let alone on such short notice. While the implications for supply chains everywhere are profound, the food system may be disproportionally affected. People will continue to eat, but where they obtain their food has changed dramatically. This has contributed to logistical problems in the supply chain, from not having enough workers in the field for processing or trucks on the roads, to problems of redirecting

\section{Figure 1. U.S. Food Expenditures by Outlet, 1987-2018}

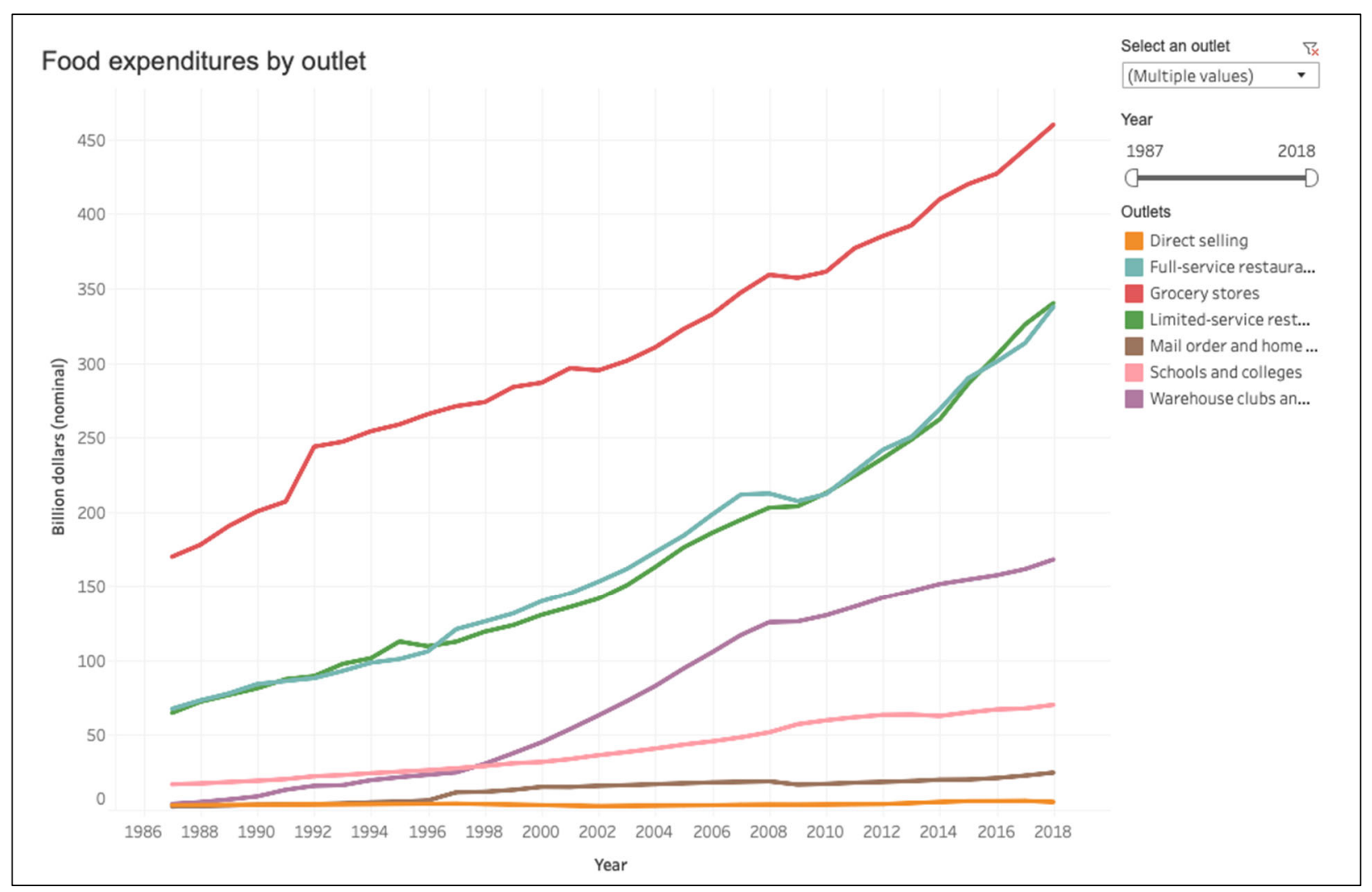

Source: U.S. Department of Agriculture Economic Research Service (n.d.). 
transportation contracts to get food to the right place at the right time, and bottlenecks in processing because of packaging and labeling requirements (Held, 2020; Poppick, 2020). These factors are compounded by the time-sensitive and perishable nature of food products and the reproduction cycles of agricultural commodities, as well the vulnerability to COVID-19 infections of workers in the food system.

\section{References}

Elitzak, H., \& Okrent, A. (2020). New U.S. food expenditure estimates find food-away-fromhome spending is higher than previous estimates. Amber Waves. Retrieved from https://www.ers.usda.gov/amber-waves/2018/november/new-us-food-expenditure-estimates-find-food-awayfrom-home-spending-is-higher-than-previous-estimates/

Held, L. (2020, April 15). Food Distribution 101: What happens when the food supply is disrupted by a pandemic. Civil Eats. Retrieved from https://civileats.com/2020/04/15/food-distribution-101-what-happens-when-the-foodsupply-is-disrupted-by-a-pandemic/

Poppick, L. (2020, March 26). The effects of COVID-19 will ripple through food systems. Scientific American. Retrieved from https://www.scientificamerican.com/article/the-effects-of-covid-19-will-ripple-through-food-systems/

U.S. Department of Agriculture Economic Research Service. (n.d.). Food expenditures by outlet [nteractive chart]. Retrieved April 29, 2020, from https://www.ers.usda.gov/data-products/food-expenditure-series/interactive-charts-food-expenditures/\#outlet
Table 1. U.S. Food Expenditure by Outlet, 2018

\begin{tabular}{lcc}
\hline & Amount (\$bn) & Percent \\
\hline Grocery stores & $\$ 460.0$ & $27.2 \%$ \\
\hline Limited-service restaurants & 340.2 & 20.1 \\
\hline Full-service restaurants & 337.8 & 20.0 \\
\hline Warehouse clubs and supercenters & 168.0 & 9.9 \\
\hline Other stores and foodservice & 78.9 & 4.7 \\
\hline Schools and colleges & 70.2 & 4.1 \\
\hline Food furnished and donated & 45.6 & 2.7 \\
\hline Retail stores and vending & 38.6 & 2.3 \\
\hline Hotels and motels & 34.9 & 2.1 \\
\hline Recreational places & 33.8 & 2.0 \\
\hline Mail order and home delivery & 24.8 & 1.5 \\
\hline Other food away from home stores & 24.3 & 1.4 \\
\hline Convenience stores & 14.0 & 0.8 \\
\hline Mass merchandisers & 9.2 & 0.5 \\
\hline Direct selling & 5.2 & 0.3 \\
\hline Drinking places & 5.2 & 0.3 \\
\hline Home production and donations & 2.3 & 0.1 \\
\hline Total & $\$ 1,693.0$ & $100.0 \%$ \\
\hline
\end{tabular}

Source: U.S. Department of Agriculture Economic Research Service, n.d. 